\title{
Conceptions of Scientific Progress in Scientific Practice: An Empirical Study
}

\author{
Moti Mizrahi \\ Florida Institute of Technology
}

\begin{abstract}
The aim of this paper is to contribute to the debate over the nature of scientific progress in philosophy of science by taking a quantitative, corpus-based approach. By employing the methods of data science and corpus linguistics, the following philosophical accounts of scientific progress are tested empirically: the semantic account of scientific progress (i.e., scientific progress in terms of truth), the epistemic account of scientific progress (i.e., scientific progress in terms of knowledge), and the noetic account of scientific progress (i.e., scientific progress in terms of understanding). Overall, the results of this quantitative, corpus-based study lend some empirical support to the epistemic and the noetic accounts over the semantic account of scientific progress, for they suggest that practicing scientists use the terms 'knowledge' and 'understanding' significantly more often than the term 'truth' when they talk about the aims or goals of scientific research in their published works. But the results do not favor the epistemic account over the noetic account, or vice versa, for they reveal no significant differences between the frequency with which practicing scientists use the terms 'knowledge' and 'understanding' when they talk about the aims or goals of scientific research in their published works.
\end{abstract}

Keywords: aim of science; corpus linguistics; empirical philosophy of science; goal of science; knowledge; scientific progress; truth; understanding

\section{Introduction}

According to Chang (2007, p. 1), "Scientific progress remains one of the most significant issues in the philosophy of science today." Following the publication of Bird's (2007) seminal paper on scientific progress, an exchange ensued between Bird (2008), Rowbottom (2008), (2015), and Niiniluoto (2014) on the merits of various philosophical accounts of scientific progress. Bird (2007) defends an epistemic account of scientific progress, according to which scientific progress consists in the accumulation of knowledge. Bird (2008) characterizes the epistemic account as follows:

(E) An episode constitutes scientific progress precisely when it shows the accumulation of scientific knowledge (Bird 2008, p. 279).

Against (E), Rowbottom (2008) defends a semantic account, according to which scientific progress should be understood in terms of truth, not knowledge. Bird (2008) characterizes the semantic account as follows:

(S) An episode constitutes scientific progress precisely when it either (a) shows the accumulation of true scientific belief, or (b) shows increasing approximation to true scientific belief (Bird 2008, p. 279). 
In another paper on scientific progress, Rowbottom (2010, p. 245) endorses (S) explicitly when he writes:

I wish to emphasise that the semantic view of scientific progress, which Bird (2007) correctly takes me to prefer as an alternative to the epistemic view, only requires that science makes progress by discovering new truths. Such truths could take the form of ' $T_{1}$ is approximately empirically adequate in the class of circumstances $C$ ', or even ' $T_{2}$ is false', and so on (emphasis added).

Niiniluoto (2014) criticizes Rowbottom's arguments for (S) over (E), but he also defines scientific progress in semantic terms. Specifically, he argues that "scientific progress can be defined by increasing verisimilitude" (Niiniluoto 2014, p. 77). For Niiniluoto (2014, p. 75), "Historical case studies, which illustrate progress as increasing truthlikeness include shifts from Ptolemy to Snell's law of refraction," among others. Rowbottom (2015) has responded to Niiniluoto (2014) and the debate rages on. ${ }^{1}$

Against (E) and (S), Dellsén (2016) argues for an understanding-based account of scientific progress. According to the "noetic account" of scientific progress, science "makes cognitive progress precisely when it increases our understanding of some aspect of the world" (Dellsén 2018a, p. 451). As Dellsén (2018b) explains, "Unlike Bird's epistemic account, [the noetic account] does not require that scientists have justification for, or even belief in, the explanations or predictions they propose." By contrast, Mizrahi and Buckwalter (2014) conduct an empirical study of intuitive judgments about scientific progress and find that they are sensitive to (internal) justification. Moreover, Park (2017) criticizes the noetic account and argues in favor of an epistemic or knowledge-based account, along the lines of (E). Dellsén (2018a) responds to Park (2017), Park (2019) responds to Dellsén, and the debate rages on.

In that respect, the philosophical debate over scientific progress is not about whether science makes progress. Rather, the debate is about the nature of scientific progress. That is, "How should we understand scientific progress?" (Douglas 2014, p. 55). What constitutes progress in science? Does scientific progress consist in approximation to truth? Does scientific progress consist in accumulation of knowledge? Does scientific progress consist in increasing understanding? To borrow a phrase from Laudan (1977, p. 66), the debate is over "the basic unit of scientific progress." On the semantic account, the basic unit of scientific progress is truth. On the epistemic account, the basic unit of scientific progress is knowledge. On the noetic account, the basic unit of scientific progress is understanding. ${ }^{2}$

\footnotetext{
${ }^{1}$ More recently, however, Rowbottom (2019, p. 19) has argued that scientific progress should not be defined solely in terms of increasing verisimilitude, but rather that "scientific progress more centrally involves increasing our resources for predicting and understanding how phenomena interrelate" (emphasis in original). In that respect, Rowbottom (2019, p. 22) agrees with Mizrahi (2013a) that increasing know how "is another significant means by which science can progress." For another argument against the semantic account of scientific progress, see Mizrahi (2017).

${ }^{2}$ Another philosophical account that should be mentioned here is the "functional-internalist" account of scientific progress, according to which "An episode shows scientific progress precisely when it achieves a specific goal of science, where that goal is such that its achievement can be determined by scientists at that time (e.g., solving scientific puzzles)" (Bird 2008, p. 279). Kuhn's account of scientific progress is a functional-internalist account of scientific progress, where "the solved problem is the basic unit of scientific progress" and "the aim of science is to maximize the scope of solved empirical problems" (Laudan 1977, p. 66). However, the current debate over scientific
} 
The aim of this paper is to contribute to this ongoing debate over the nature of scientific progress by taking an empirical approach. It reports the results of a quantitative, corpus-based study of the semantic, epistemic, and noetic accounts of progress. For, as van Fraassen (1994, p. 184) argues, "Any philosophical view of science is to be held accountable to actual scientific practice, scientific activity." If van Fraassen is right about this, then philosophical views of scientific progress can (and perhaps should) be held accountable to actual scientific practice, or scientific activity, as well. Philosophical accounts of scientific progress can be tested empirically against scientific practice by using the methods of data science and corpus linguistics. These methods allow for the systematic study of a large corpus of scientific texts in order to uncover patterns of usage. In particular, do practicing scientists talk about scientific progress in their published work? If so, in what terms? Do they talk about scientific progress in terms of truth, in terms of knowledge, or in terms of understanding? Finding answers to these questions empirically might help to shed new light on the nature of scientific progress by revealing how practicing scientists conceive of scientific progress. In this way, philosophical accounts of scientific progress can be held accountable to scientific practice, or scientific activity, just as van Fraassen recommends.

Furthermore, this empirical testing of philosophical accounts of scientific progress against scientific practice should be of particular interest to philosophers of science who advocate for "a conscious and organized programme of detailed and systematic study of scientific practice that does not dispense with concerns about truth and rationality" (Society for Philosophy of Science in Practice 2006-2019). To the extent that there has been a "practice turn" in philosophy of science, as some claim (Soler et al. 2014), empirical methods should be particularly useful to philosophers of science who are interested in studying scientific practices. According to the mission statement of the Society for Philosophy of Science in Practice (SPSP), "Practice consists of organized or regulated activities aimed at the achievement of certain goals" (Society for Philosophy of Science in Practice 2006-2019). Empirical methods, such as those used in this empirical study, namely, the text mining, corpus analysis, and data visualization techniques of data science and corpus linguistics, seem to be well suited for studying "actual scientific practice, scientific activity" (van Fraassen 1994, p. 184).

The structure of this paper is as follows. Section 2 consists of a description of the methods used in this quantitative, corpus-based study of conceptions of scientific progress in scientific practice. The results of this study are reported in Section 3. Section 4 contains a discussion of the implications of the results of this study as far as the philosophical debate concerning the nature of scientific progress is concerned. Overall, the results of this quantitative, corpus-based study lend some empirical support to the epistemic and the noetic accounts over the semantic account of scientific progress, for they suggest that scientists use the terms 'knowledge' and 'understanding' significantly more often than the term 'truth' when they talk about the aims or goals of scientific research in their published works. But the results do not favor the epistemic account over the noetic account, or vice versa, for they reveal no significant differences between the frequency with which practicing scientists use the terms 'knowledge' and 'understanding' when they talk about the aims or goals of scientific research in their published works.

progress in contemporary philosophy of science has been focused on the semantic, epistemic, and noetic accounts. Although see Shan (2019) for a recent defense of a functional account of scientific progress. 


\section{Methods}

This quantitative, corpus-based study is designed to test the semantic account (i.e., scientific progress in terms of truth), the epistemic account (i.e., scientific progress in terms of knowledge), and the noetic account (i.e., scientific progress in terms of understanding) of scientific progress empirically. For, on the assumption that we can learn from scientific practices, specifically, from what scientists say and do in their published works, each of these philosophical accounts of scientific progress has empirical consequences that can be tested against "actual scientific practice, scientific activity" (van Fraassen 1994, p. 184). More specifically:

- On the semantic account, which defines scientific progress in terms of truth, we would expect to find that practicing scientists talk about scientific progress in terms of truth more than knowledge or understanding in scientific publications.

- On the epistemic account, which defines scientific progress in terms of knowledge, we would expect to find that practicing scientists talk about scientific progress in terms of knowledge more than truth or understanding in scientific publications.

- On the noetic account, which defines scientific progress in terms of understanding, we would expect to find that practicing scientists talk about scientific progress in terms of understanding more than knowledge or truth in scientific publications.

It is important to emphasize, as an anonymous reviewer encouraged me to do, that these are empirical, not logically necessary, consequences of the semantic, epistemic, and noetic accounts of scientific progress. That is to say, proponents of each of these accounts of scientific progress are not necessarily committed to these empirical consequences because they could always reject the methodological assumptions that are used to derive these empirical consequences in the first place. In particular, it is open to proponents of any account of scientific progress to reject the methodological assumption that what scientists say and do in their published works can (and/or should) inform philosophical accounts of scientific progress. For example, proponents of the semantic account of scientific progress, which construes scientific progress in terms of truth, are not necessarily committed to the empirical claim that practicing scientists use the term 'truth' more than other terms for the basic units of progress, such as 'knowledge' and 'understanding', when they talk about the aims and/or goals of scientific research in their published works unless they accept the methodological assumption that philosophical accounts of scientific progress are to be tested against what practicing scientists say and do in their published works. Proponents of the semantic account, or any other account of scientific progress for that matter, might reject this methodological assumption for metaphilosophical reasons if, say, they prefer testing philosophical accounts of scientific progress against intuitions, as Bird (2007) does, ${ }^{3}$ or case studies from the history of science, as Niiniluoto (2014) does. Or they might insist that the philosophical debate over the nature of scientific progress is a purely normative debate, with no descriptive dimensions whatsoever, and thus empirical evidence cannot settle any questions concerning the nature of scientific progress. As Niiniluoto (2019) puts it:

it can be argued [...] that progress should not be defined by the actual developments of science: the definition of progress should give us a normative standard for appraising the

\footnotetext{
${ }^{3}$ Cf. Cevolani and Tambolo (2013) whose intuitions seem to differ from Bird's.
} 
choices that the scientific communities have made, could have made, are just now making, and will make in the future. The task of finding and defending such standards is a genuinely philosophical one which can be enlightened by history and sociology but which cannot be reduced to empirical studies of science (emphasis in original).

In this paper, I will try to steer clear of this metaphilosophical debate over how to do philosophy of science, if I can. For I am not arguing that testing philosophical accounts of scientific progress against actual scientific practices empirically is better than testing them against intuitions or case studies from the history of science. Rather, I am simply proposing such empirical testing of philosophical accounts of scientific progress as an alternative (neither better nor worse) to testing them against intuitions or case studies.

Now, assuming that we do want to test philosophical accounts of scientific progress against scientific practices empirically, since we think that the results of such empirical studies might help to shed new light on the nature of scientific progress, the methods of text mining and corpus analysis allow us to examine a large corpus of scientific texts (i.e., articles and book chapters written by practicing scientists and published in scientific journals and books) in order to find out how practicing scientists conceive of progress in scientific practice (i.e., in their published work). Such data can be mined from JSTOR Data for Research (www.jstor.org/dfr/). Researchers can use JSTOR DfR to create datasets, including metadata, n-grams, and word counts, for most of the articles and book chapters contained in the JSTOR database. Accordingly, we can mine the JSTOR database for instances of the terms 'truth', 'knowledge', and 'understanding' in order to see whether, and to what extent, practicing scientists use these terms when they talk about scientific progress in their published works. If the semantic account of scientific progress is true, we should find that practicing scientists use the term 'truth' more frequently than the terms 'knowledge' or 'understanding' when they discuss scientific progress in scientific publications. If the epistemic account of scientific progress is true, we should find that practicing scientists use the term 'knowledge' more frequently than the terms 'truth' or 'understanding' when they discuss scientific progress in scientific publications. And if the noetic account of scientific progress is true, we should find that practicing scientists use the term 'understanding' more frequently than the terms 'knowledge' or 'truth' when they discuss scientific progress in scientific publications. Again, these are empirical, not logically necessary, consequences of the semantic, epistemic, and noetic accounts of scientific progress that can be derived from these accounts only by assuming that there is a descriptive dimension to the question of scientific progress that can be investigated empirically. This is not to say that the question of scientific progress can be settled empirically. Instead, it is merely to say that we might be able to gain some insights from an empirical investigation of the ways in which practicing scientists talk about scientific progress.

The methods of text mining and corpus analysis allow us to overcome the limitations of relying on selected case studies from the history of science. For those case studies may or may not be representative of science as a whole. As Pitt (2001, p. 373) puts it, "if one starts with a case study, it is not clear where to go from there - for it is unreasonable to generalize from one case or even two or three." After all, examples of practicing scientists talking about scientific progress in terms of truth, knowledge, and understanding can be found in scientific publications rather easily. For example (emphasis added): 
Progress in vegetation science can be found neither in generating untestable hypotheses about vegetation as such nor in more and more detailed descriptions of local vegetation types. [...] The definition of progress depends on the definition of truth (Wiegleb 1989, p. 27).

In this case, progress in vegetation science is discussed in terms of truth. ${ }^{4}$ One might worry, however, whether this example is representative of science as a whole. ${ }^{5}$ By using the text mining, corpus analysis, and data visualization techniques of data science and corpus linguistics, we can study a large corpus of scientific texts in order to uncover patterns of usage. Those patterns of usage, in turn, might shed some light on the ways in which practicing scientists conceive of scientific progress in scientific practice (i.e., in scientific research published in scientific journals). ${ }^{6}$

Of course, empirical methodologies have limitations of their own. As far as the corpusbased methods used in this quantitative study are concerned, there are two major limitations. First, we can only study and analyze what is explicitly mentioned in the corpus. For the purpose of this corpus-based study, then, the corpus of scientific texts must contain explicit mentions of the terms 'truth', 'knowledge', and 'understanding', for us to be able to analyze patterns of usage. As mentioned above, examples of practicing scientists talking about scientific progress in terms of truth, knowledge, and understanding in scientific publications are not difficult to find, but we would like to know how frequently practicing scientists use these terms, and whether there are significant differences in the frequency with which these terms are used by practicing scientists.

In that respect, it is important to acknowledge the possibility that practicing scientists could be using the terms 'truth', 'knowledge', and 'understanding' in ways that differ from the ways in which philosophers are using these terms. For example, it is possible that practicing scientists use the term 'knowledge' to mean something like "true belief" rather than "justified true belief." Relatedly, it is also worth noting that the notions of truth, knowledge, and understanding are often taken as givens and remain unanalyzed in philosophical accounts of scientific progress. For example, according to Bird (2007), who defends the epistemic account of scientific progress, knowledge does not mean "justified true belief." Rather, Bird (2007, p. 87) takes his argument for the epistemic account of scientific progress "to support Williamson's view (Williamson 2000) that knowledge is the central epistemic concept and does not have an analysis." Likewise, some proponents of the semantic account of scientific progress tend to leave the notion of truth unanalyzed, while others take it that truth is correspondence to reality (or to facts). For example, on Niiniluoto's (2014, p. 74) similarity approach, truthlikeness is explicated "as distance from the target $\mathrm{C}^{*}$ which is the most informative true statement in [a semantically

\footnotetext{
${ }^{4}$ Cf. Mizrahi (2013a), where two case studies (namely, Landsteiner's discovery of blood groups and Pavlov's work on the physiology of digestion) are taken as providing support for an epistemic account of scientific progress.

${ }^{5}$ On the methodological problems associated with using case studies from the history of science as evidence in philosophy of science, see Sauer and Scholl (2016, pp. 1-10), Bolinska and Martin (2020), and Mizrahi (2020). ${ }^{6}$ On the application of the methods of data science and corpus linguistics, such as data mining and corpus analysis, to philosophy of science, see Mizrahi (2013b) and Mizrahi (2016). For an example of an application of survey and other methodologies from the social sciences to the question of scientific progress in philosophy of science, see Mizrahi and Buckwalter (2014). See also Beebe and Dellsén (2020).
} 
determinate language] L" (emphasis added). Like Bird (2007), who does not offer an analysis of the notion of knowledge, Niiniluoto (2014) does not offer an analysis of what makes $\mathrm{C}^{*}$ true.

Rather, $\mathrm{C}^{*}$ is the target from which a theory's degree of truthlikeness is determined as a measure of distance. That is, "The degree of truthlikeness $\operatorname{Tr}\left(\mathrm{H}, \mathrm{C}^{*}\right)$ is [...] 1 minus the distance between $\mathrm{H}$ and $\mathrm{C}^{*}$ " (Niiniluoto 2014, p. 74). For Cevolani and Tambolo (2013, p. 928), who defend a semantic account of scientific progress in terms of increasing verisimilitude, there is a "distinction between real and estimated progress," which "is motivated by the fact that there is no way to ascertain whether a given belief exhibits a genuine correspondence to "the real world" (emphasis added), where "truth is defined as correspondence between interpreted sentences in a language $L$ and facts" (Tambolo 2014, p. 208). Finally, Dellsén (2018, p. 7) admits that "the concept of 'understanding' is itself a hotly debated topic, so there is little agreement on what is required for someone to possess understanding." For this reason, Dellsén (2016, p. 75) stipulates that, on his noetic account of scientific progress, scientific understanding means grasping "how to correctly explain and/or predict some aspects of the target in the right sort of circumstances." To Dellsén (2016, p. 75), this "seems [...] to be a very natural way to conceive of the kind of understanding that is of relevance to the sciences." But it is by no means generally accepted among epistemologists, as Dellsén $(2018$, p. 7) knows well. The point here is not meant to be a criticism against the semantic, epistemic, and noetic accounts of scientific progress. Surely, when giving a philosophical account of some phenomenon, one has to start somewhere, and so some notions are bound to be taken for granted, stipulated, or remain unanalyzed. Rather, the point is that the terms 'truth', 'knowledge', and 'understanding' could be used in different ways. For example, suppose that practicing scientists use the term 'knowledge' to mean something like "true belief" (without justification). Suppose further that we find practicing scientists using the term 'knowledge' significantly more often than the terms 'truth' or 'understanding' when they talk about the aims and goals of scientific research in their published works. In that case, proponents of the semantic account of scientific progress could argue that the prevalence of "knowledge" talk actually supports the semantic account of scientific progress because, for scientists, "knowledge" means "true belief."7 This is why the results of this empirical study, like the results of any other empirical study, should not to be interpreted as conclusive evidence for or against any philosophical account of scientific progress.

Second, as with many empirical methodologies, there may be some false positives and/or false negatives. As far as the text-mining method employed in this corpus-based study is concerned, false positives would be instances of the terms 'truth', 'knowledge', or 'understanding' in scientific publications that are not about progress in science. Take, for example, the following occurrence of 'truth' in a scientific text (emphasis added):

Certainly, we all dream of a one-gene-determining-one-phenotype scenario, but this actually might be far from the truth in biological systems (Heng and Cao 2006, p. 52).

In this case, the term 'truth' is used but not in the context of talk about scientific progress per se. Therefore, we would like our text-mining methodology to ignore such instances of the terms 'truth', 'knowledge', and 'understanding' that are not about scientific progress per se. We can do so by refining our text-mining methodology. Here is how.

\footnotetext{
${ }^{7}$ Many thanks to an anonymous reviewer for this point.
} 
As Niiniluoto (2019) points out, the philosophical debate over the nature of scientific progress is "concerned with axiological questions about the aims and goals of science" (emphasis added). This is because "Progress is a goal-relative concept" (Niiniluoto 2019; emphasis in original). On the semantic account of scientific progress, the aim or goal of science is to get closer to the truth. On the epistemic account of scientific progress, the aim or goal of science is to accumulate knowledge. On the noetic account of scientific progress, the aim or goal of science is to increase understanding. Accordingly, to make sure that instances of the terms 'truth', 'knowledge', and 'understanding' in scientific publications are about scientific progress, and thereby minimize the number of false positives our text-mining methodology might identify, we can search for the terms for the basic units of progress 'truth', 'knowledge', and 'understanding' in the context of the progress terms 'aim' and 'goal'. When we combine the terms for the basic units of progress, namely, 'truth', 'knowledge', and 'understanding', with the progress terms, namely, 'aim' and 'goal', we get the search pairs listed in Table 1.

Table 1. Search pairs for the semantic, epistemic, and noetic accounts of scientific progress

\begin{tabular}{|l|l|l|}
\hline & aim & goal \\
\hline Truth & aim truth & goal truth \\
\hline knowledge & aim knowledge & goal knowledge \\
\hline understanding & aim understanding & goal understanding \\
\hline
\end{tabular}

By pairing the terms for the basic units of progress with the progress terms, as listed in Table 1, we can be quite confident that our text-mining method would pick out instances of the terms for the basic units of progress in the corpus that occur in the context of talk about the aims or goals of scientific research. "In the context of" is operationalized using the operator $\sim$ and the number of words between the terms for the basic units of progress and the progress terms. For the purposes of this corpus-based study, the number of words between the terms for the basic units of progress and the progress terms is ten. This is because, according to the Concise Oxford Companion to the English Language, "written English sentences might average 20 words in length" and many English sentences are complex sentences, i.e., they consist of two main clauses joined by a coordinating conjunction. Accordingly, we can be quite confident that instances of the terms for the basic units of progress occur in the context of talk about the aims or goals of scientific research if those terms occur in the same clause. Since an average English sentence is twenty words long, consisting of two main clauses, we should allow for no more than ten words between a term for the basic units of progress and a progress term. ${ }^{8}$ In practice, this means that we search for each of the terms for the basic units of progress within ten words of each of the progress terms, e.g., ("aim truth" 10), ("goal knowledge" 10), ("aim understanding" 10 ), and so on. This text-mining methodology is designed to minimize the number of false positives, i.e., instances of the terms for the basic units of progress that are not about scientific progress, by ensuring that instances of these terms in text are anchored to the progress terms, namely, 'aim' or

\footnotetext{
${ }^{8}$ In that respect, the default setting for proximity searches in databases like JSTOR and ProQuest's Literature Online (LION) is ten words.
} 
'goal', while allowing for only ten words between a term for a basic unit of progress, such as 'truth', and a progress term, such as 'goal'.

Moreover, this text-mining methodology is also designed to minimize the number of false negatives. As far as the text-mining method employed in this corpus-based study is concerned, false negatives could occur when we search for a specific term $t$ in a corpus, but do not find it, even though the corpus contains a synonym of $t$. For example, although unlikely, it is possible that our corpus of scientific texts contains no instances of 'aim', and so a search for 'aim' would return zero results, because practicing scientists use a synonym for 'aim', such as 'goal', when they talk about scientific progress in all the publications that make up our corpus. By pairing the terms for the basic units of progress with the progress terms 'aim' and 'goal', as listed in Table 1, we can be quite confident that our text-mining method would pick out instances of the terms for the basic units of progress in the corpus that occur in the context of talk about the aims or goals of scientific research, and thereby minimize the number of false negatives in our datasets.

For example, this text-mining methodology will identify the following as a positive result for the basic unit of progress 'truth' in the context of talk about scientific goals (emphasis added):

If scientists are unwilling to make this small extra step, it must be questioned whether they are genuinely interested in uncovering the truth - the ultimate goal of science-or whether they are pursuing their own agenda (Vink et al. 2012, p. 452).

This is precisely what we would like our text-mining method to do in this case because truth is singled out here as the ultimate goal of science. So this is a genuine instance of 'truth' being used as a basic unit of progress in scientific practice and our text-mining methodology will count it as a positive result of ("goal truth" 10 ) because there are less than ten words between the term for the basic unit of progress 'truth' and the progress term 'goal'. On the other hand, the following instance of 'truth' will not be counted as a positive result of ("aim truth" 10 ) by our text-mining method because there are more than ten words between the term for the basic unit of progress 'truth' and the progress term 'aim' (emphasis added):

If the basic aim is to estimate the mean value of a biological variable over a study area, the simple random sampling design, one of the simplest probabilistic designs, gives the results closest to truth (Albert et al. 2010, p. 1034).

This is precisely what we would like our text-mining method to do in this case as well because the term 'aim' is used to talk about estimating means, not about making progress in science. Note that the sentence in the quotation above is a complex sentence where the term for the basic unit of progress 'truth' and the progress term 'aim' do not occur in the same clause.

In that respect, it is worth noting that, although they are synonyms for the progress terms 'aim' and 'goal', the terms 'objective' and 'end' are too problematic to use as practice terms to search for in this quantitative, corpus-based study. For the terms 'objective' and 'end' have many more meanings besides being synonymous with 'aim' and 'goal'. As philosophers know all too well, the term 'objective' is particularly problematic. Janack (2002, p. 275) identifies no less than 
thirteen distinct uses of "objectivity." The same can be said about 'end', which can be used to talk about the end-result of an activity, but also the final part of a period of time or the conclusion of a story.

It is also important to note that, just like any other empirical study, the results of this quantitative, corpus-based study are not to be interpreted as conclusive evidence for or against any philosophical account of scientific progress. Nor are the methods used in this study the only (or even the best) methods to study how practicing scientists conceive of scientific progress in scientific practice. Rather, the methods and results of this study are supposed to help shed new light on the question of scientific progress in philosophy of science. Other studies, which make use of different empirical methods, such as survey procedures, can do the same (see, e.g., Mizrahi and Buckwalter 2014, and Beebe and Dellsén 2020).

\section{Results}

The JSTOR database allows for searches by subject, such as Biological Sciences, Physics, and Sociology. In order to have a large and diverse sample that would be representative of science as a whole, searches were conducted on data mined from the following subjects in the JSTOR database: Anthropology, Archeology, Astronomy, Biological Sciences, Economics, Geography, Geology, Linguistics, Mathematics, Paleontology, Physics, Psychology, Sociology, Statistics, and Zoology. That way, the datasets for this study contain representative disciplines from the life sciences (namely, Biological Sciences and Zoology), the physical sciences (namely, Astronomy and Physics), the social sciences (namely, Anthropology and Sociology), and the formal sciences (namely, Mathematics and Statistics).

For each of the aforementioned subjects, searches were conducted for the terms for the basic units of progress 'truth', 'knowledge', and 'understanding' in the context of (i.e., within ten words of) the progress terms 'aim' and 'goal' (see Table 1). The search results for the terms for the basic units of progress in the context of (i.e., within ten words of) the progress term 'aim' in each subject are listed in Table 2. All searches were conducted on February 21, 2020 and results were verified on June 8, 2020.

Table 2. Total number of publications, and those that contain the terms for the basic units of progress in the context of talk about scientific aims, by subject (Source: JSTOR Data for Research)

\begin{tabular}{|l|r|l|l|l|}
\hline & Total & $\begin{array}{l}\text { "aim } \\
\text { truth" } 10\end{array}$ & $\begin{array}{l}\text { "aim } \\
\text { knowledge" 10 }\end{array}$ & $\begin{array}{l}\text { "aim } \\
\text { understanding” 10 }\end{array}$ \\
\hline Anthropology & 341313 & 160 & 689 & 588 \\
\hline Archaeology & 327238 & 42 & 219 & 377 \\
\hline Astronomy & 18427 & 3 & 4 & 7 \\
\hline $\begin{array}{l}\text { Biological } \\
\text { Sciences }\end{array}$ & 1331986 & 149 & 1100 & 1470 \\
\hline Economics & 730341 & 111 & 650 & 675 \\
\hline
\end{tabular}




\begin{tabular}{|l|r|r|r|r|}
\hline Geography & 175314 & 31 & 289 & 240 \\
\hline Geology & 15556 & 1 & 12 & 9 \\
\hline Linguistics & 204098 & 85 & 239 & 202 \\
\hline Mathematics & 367900 & 82 & 306 & 424 \\
\hline Paleontology & 35403 & 2 & 14 & 21 \\
\hline Physics & 5834 & 4 & 5 & 14 \\
\hline Psychology & 97110 & 90 & 293 & 342 \\
\hline Sociology & 724387 & 413 & 1587 & 1523 \\
\hline Statistics & 135538 & 19 & 129 & 150 \\
\hline Zoology & 257911 & 7 & 118 & 115 \\
\hline
\end{tabular}

Since some subjects in the JSTOR database contain more publications than others, we need to compare proportions rather than raw counts. The proportions of the terms for the basic units of progress in the context of (i.e., within ten words of) the progress term 'aim' in each subject are depicted in Figure 1.

Figure 1. Proportions of publications that contain the terms for the basic units of progress in the context of talk about scientific aims by subject (Source: JSTOR Data for Research) 


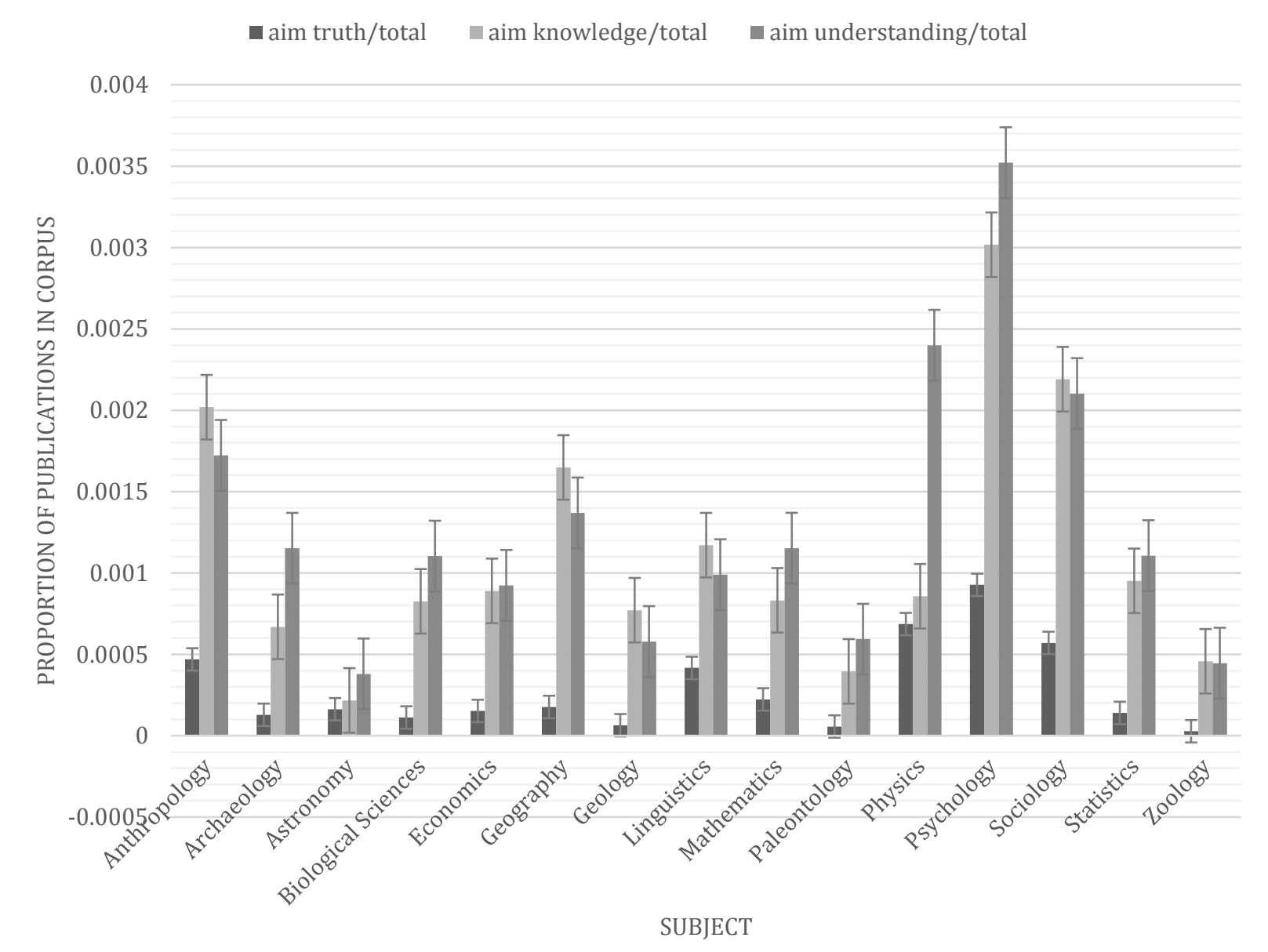

As we can see from Figure 1, the terms for the basic units of progress do not occur all that frequently in the context of talk about aims in scientific publications (less than $0.4 \%$ overall). To the extent that they do occur, however, it is 'understanding' that occurs most frequently overall, followed by 'knowledge', and then 'truth'. The exceptions are Anthropology, Geography, Geology, Linguistics, Sociology, and Zoology, in which 'knowledge' occurs more frequently than 'understanding' in the context of aim talk.

Independent-samples t-tests were conducted to compare the proportions of scientific publications that contain the terms for the basic units of progress in the context of (i.e., within ten words of) the progress term 'aim' across the subjects tested in this study. First, there was a significant difference between the proportion of ("aim knowledge" 10$)$ publications $(\mathrm{M}=0.001$, $\mathrm{SD}=0.0007, \mathrm{~N}=15)$ and ("aim truth" 10$)$ publications $(\mathrm{M}=0.0002, \mathrm{SD}=0.0002, \mathrm{~N}=15)$, $t(17)=-4.002, p<0.00$, two-tailed. Second, there was a significant difference between the proportion of ("aim understanding" 10) publications $(\mathrm{M}=0.001, \mathrm{SD}=0.0008, \mathrm{~N}=15)$ and ("aim truth" 10) publications $(\mathrm{M}=0.0002, \mathrm{SD}=0.0002, \mathrm{~N}=15), \mathrm{t}(16)=-3.41, \mathrm{p}<0.00$, twotailed. Finally, there was no significant difference between the proportion of ("aim knowledge" 10) publications $(\mathrm{M}=0.0011, \mathrm{SD}=0.0007, \mathrm{~N}=15)$ and ("aim understanding" 10 ) publications $(\mathrm{M}=0.0013, \mathrm{SD}=0.0008, \mathrm{~N}=15), \mathrm{t}(28)=-0.59, \mathrm{p}<0.55$, two-tailed. These results suggest that there is significantly more talk about the aim of scientific research in terms of 
knowledge than in terms of truth, and there is also significantly more talk about the aim of scientific research in terms of understanding than in terms of truth, but there isn't significantly more talk about the aim of scientific research in terms of understanding than in terms of knowledge.

In order to make sure that the text-mining methodology described in Section 2 returns genuine instances of the terms for the basic units of progress in the context of talk about the aims of scientific research, one result from the life sciences, one result from the physical sciences, one result from the social sciences, and one result from the formal sciences were selected at random (emphasis added):

1. Life Sciences: "The aims of our research are therefore twofold: firstly, to increase our understanding of migratory population dynamics in declining populations of shorebirds..." (Dhanjal-Adams 2019, p. 798).

2. Physical Sciences: "We studied their scaling relations with the aim of understanding the role of SMBHs in the evolution of galaxies" (Beifiori 2011, p. 514).

3. Social Sciences: "The aim of the present research is to contribute to the knowledge of the complex processes of migration and social mobility and their mutual interconnections in general..." (Guhlich 2017, p. 324).

4. Formal Sciences: "there is a ground truth that statisticians can aim to discover" (Bogdan et al. 2015, p. 1104).

In each of these examples, practicing scientists talk about the aims of their research in terms of understanding, knowledge, or truth. Statistically speaking, however, there is no significant difference between talk of the aim of scientific research in terms of increasing understanding than talk of the aim of scientific research in terms of advancing knowledge. Both talk of the aim of scientific research in terms of knowledge and talk of the aim of scientific research in terms of understanding, however, are significantly more frequent than talk of the aim of scientific research in terms of truth.

When we search for the terms for the basic units of progress in the context of talk about the goals of scientific research, we find somewhat similar results. The search results for the terms for the basic units of progress in the context of (i.e., within ten words of) the progress term 'goal' in each subject are listed in Table 3.

Table 3. Total number of publications, and those that contain the terms for the basic units of progress in the context of talk about scientific goals, by subject (Source: JSTOR Data for Research)

\begin{tabular}{|l|r|l|l|l|}
\hline & Total & $\begin{array}{l}\text { "goal } \\
\text { truth" }\end{array}$ & $\begin{array}{l}\text { "goal } \\
\text { knowledge" 10 }\end{array}$ & $\begin{array}{l}\text { "goal } \\
\text { understanding" 10 }\end{array}$ \\
\hline Anthropology & 341313 & 158 & 718 & 847 \\
\hline Archaeology & 327238 & 32 & 167 & 362 \\
\hline Astronomy & 18427 & 3 & 11 & 34 \\
\hline
\end{tabular}




\begin{tabular}{|l|r|r|r|r|}
\hline Biological Sciences & 1331986 & 129 & 1243 & 2286 \\
\hline Economics & 730341 & 121 & 609 & 709 \\
\hline Geography & 175314 & 22 & 144 & 174 \\
\hline Geology & 15556 & 5 & 7 & 12 \\
\hline Linguistics & 204098 & 68 & 328 & 291 \\
\hline Mathematics & 367900 & 75 & 360 & 552 \\
\hline Paleontology & 35403 & 3 & 18 & 50 \\
\hline Physics & 5834 & 10 & 17 & 27 \\
\hline Psychology & 97110 & 88 & 708 & 781 \\
\hline Sociology & 724387 & 559 & 2045 & 2054 \\
\hline Statistics & 135538 & 21 & 132 & 155 \\
\hline Zoology & 257911 & 14 & 130 & 227 \\
\hline
\end{tabular}

Again, since some subjects in the JSTOR database contain more publications than others, we need to compare proportions rather than raw counts. The proportions of the terms for the basic units of progress in the context of (i.e., within ten words of) the progress term 'goal' in each subject are depicted in Figure 2.

Figure 2. Proportions of publications that contain the terms for the basic units of progress in the context of talk about scientific goals by subject (Source: JSTOR Data for Research) 


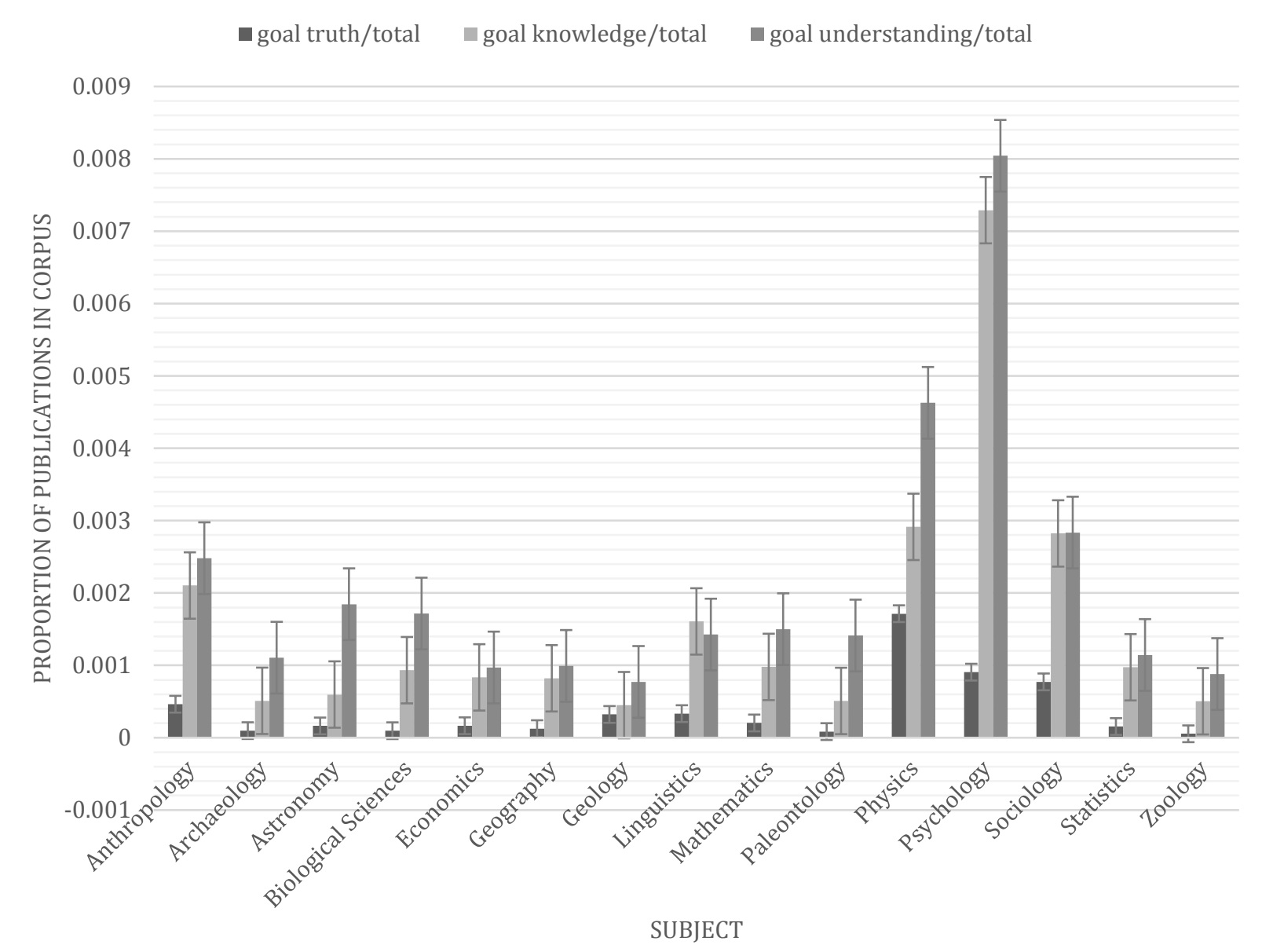

As we can see from Figure 2, the terms for the basic units of progress do not occur all that frequently in the context of talk about goals in scientific publications, either (less than $0.9 \%$ overall). To the extent that they do occur, however, it is 'understanding' again that occurs most frequently overall, followed by 'knowledge', and then 'truth'. This time, the only exception is Linguistics, where 'knowledge' still occurs more frequently than 'understanding' in the context of talk about goals, as in the context of talk about aims. Unlike the context of aim talk, 'understanding' now occurs more frequently than 'truth' or 'knowledge' in the context of goal talk in Anthropology, Geography, Geology, Sociology, and Zoology.

Independent-samples t-tests were conducted to compare the proportions of scientific publications that contain the terms for the basic units of progress in the context of (i.e., within ten words of) the progress term 'goal' across the subjects tested in this study. First, there was a significant difference between the proportion of ("goal knowledge" 10) publications $(\mathrm{M}=$ $0.001, \mathrm{SD}=0.001, \mathrm{~N}=15)$ and ("goal truth" 10$)$ publications $(\mathrm{M}=0.0003, \mathrm{SD}=0.0004, \mathrm{~N}=$ $15), t(16)=-2.56, p<0.02$, two-tailed. Second, there was a significant difference between the proportion of ("goal understanding" 10) publications $(\mathrm{M}=0.002, \mathrm{SD}=0.001, \mathrm{~N}=15)$ and ("goal truth" 10) publications $(\mathrm{M}=0.0003, \mathrm{SD}=0.0004, \mathrm{~N}=15), \mathrm{t}(16)=-3.41, \mathrm{p}<0.00$, twotailed. Finally, there was no significant difference between the proportion of ("goal knowledge" 10) publications $(\mathrm{M}=0.001, \mathrm{SD}=0.001, \mathrm{~N}=15)$ and ("goal understanding" 10$)$ 
publications $(\mathrm{M}=0.002, \mathrm{SD}=0.001, \mathrm{~N}=15), \mathrm{t}(28)=-0.78, \mathrm{p}<0.44$, two-tailed. These results suggest that there is significantly more talk about the goal of scientific research in terms of knowledge than in terms of truth, and there is also significantly more talk about the goal of scientific research in terms of understanding than in terms of truth, but there isn't significantly more talk about the goal of scientific research in terms of understanding than in terms of knowledge.

In order to make sure that the text-mining methodology described in Section 2 returns genuine instances of the terms for basic units of progress in the context of talk about the goals of scientific research, one result from the life sciences, one result from the physical sciences, one result from the social sciences, and one result from the formal sciences were selected at random (emphasis added):

1. Life Sciences: "With continually advancing technologies and increasingly sophisticated bioinformatics tools at our disposal, data production capacity will only increase and, without care, we risk losing sight of the primary goal - to advance knowledge rather than generate data" (Hall 2006, p. 465).

2. Physical Sciences: "Our Palaeogene sediment studies will address these questions that are related to our primary science goal of understanding subduction initiation..." (Sutherland 2017, p. 168).

3. Social Sciences: "We provide the first causal estimate of the impact of attending SEED schools on academic achievement, with the goal of understanding whether changing a student's environment is an effective strategy to increase achievement among the poor" (Curto and Fryer Jr. 2014, p. 65).

4. Formal Sciences: "Our goal is to establish the truth of this result for a field of arbitrary characteristic" (Lichtman 1981, p. 188).

In each of these examples, practicing scientists talk about the goals of their research in terms of understanding, knowledge, or truth. Statistically speaking, however, there is no significant difference between talk of the goal of scientific research in terms of increasing understanding than talk of the goal of scientific research in terms of advancing knowledge. Both talk of the goal of scientific research in terms of knowledge and talk of the goal of scientific research in terms of understanding, however, are significantly more frequent than talk of the goal of scientific research in terms of truth.

\section{Discussion}

As discussed in Section 2, this corpus-based study was designed to test philosophical views of scientific progress - namely, the semantic account (i.e., scientific progress in terms of truth), the epistemic account (i.e., scientific progress in terms of knowledge), and the noetic account (i.e., scientific progress in terms of understanding) — against scientific practice. For, on the assumption that we can learn from scientific practices, specifically, from what scientists say and do in their published works, each of these philosophical accounts of scientific progress has empirical consequences that can be tested against scientific practice. More specifically: 
- On the semantic account, which defines scientific progress in terms of truth, we would expect to find that practicing scientists talk about scientific progress in terms of truth more than knowledge or understanding in scientific publications.

- On the epistemic account, which defines scientific progress in terms of knowledge, we would expect to find that practicing scientists talk about scientific progress in terms of knowledge more than truth or understanding in scientific publications.

- On the noetic account, which defines scientific progress in terms of understanding, we would expect to find that practicing scientists talk about scientific progress in terms of understanding more than knowledge or truth in scientific publications.

Overall, the results of this study suggest that the terms for the basic units of progress, namely, 'truth', 'knowledge', and 'understanding', do not occur all that frequently in scientific publications (less than $0.4 \%$ in the context of talk about the aims of scientific research and less than $0.9 \%$ in the context of talk about the goals of scientific research). To the extent that they do occur, however, the progress terms 'knowledge' and 'understanding' occur significantly more frequently than the progress term 'truth' in the context of talk about scientific aims or goals, as the results of independent-samples t-tests show.

These results can be construed as providing some empirical support to the epistemic and the noetic accounts over the semantic account of scientific progress, provided that the methodological assumptions of these empirical study are acceptable (see Section 2). For, as we would expect if the epistemic account of scientific progress were true, the results suggest that talk about the aims or goals of scientific research in terms of knowledge is significantly more frequent than talk about the aims or goals of scientific research in terms of truth in scientific publications. Likewise, as we would expect if the noetic account of scientific progress were true, the results suggest that talk about the aims or goals of scientific research in terms of understanding is significantly more frequent than talk about the aims or goals of scientific research in terms of truth in scientific publications. Since the results of independent-samples ttests do not point to any significant differences between the frequency with which practicing scientists use the terms 'knowledge' and 'understanding' when they talk about the aims or goals of scientific research in their published works, these results do not lend any empirical support to the epistemic account over the noetic account or to the noetic account over the epistemic account. For this reason, further studies are needed in order to determine which of these two philosophical accounts of scientific progress best captures "actual scientific practice, scientific activity" (van Fraassen 1994, p. 184).

As discussed in Section 2, like the results of other empirical studies, the results of this corpus-based study are not to be interpreted as conclusive evidence for or against any philosophical accounts of scientific progress. Rather, they are supposed to contribute to our understanding of scientific progress in scientific practice. Some philosophers of science, who prefer rational reconstructions of science (Lakatos 1971, pp. 91-136), ${ }^{9}$ as opposed to empirical studies of scientific practices, might object that we do not gain much by way of understanding the nature of science when we study scientific practices, i.e., what practicing scientists say and

\footnotetext{
${ }^{9}$ According to Machery (2016, p. 480), "Rational reconstructions reconstruct the way scientists use particular concepts," such as scientific progress.
} 
do, empirically. ${ }^{10}$ This is a methodological debate about how to do philosophy of science that is beyond the scope of this paper. For the purposes of this quantitative, corpus-based study, I take it as a methodological assumption that we can gain valuable insights about science from a systematic study of what practicing scientists say and do, specifically, what they say and do in their scholarly publications. For, as van Fraassen (1994, p. 184) puts it, "Any philosophical view of science is to be held accountable to actual scientific practice, scientific activity." Accordingly, philosophical views of scientific progress are be held accountable to actual scientific practice, scientific activity. After all, what practicing scientists say and do in their research articles in particular seems to fall under "actual scientific practice" or "scientific activity" because what scientists say and do in general falls under "actual scientific practice" or "scientific activity." As Rouse (2007, p. 84) puts it, "A philosophy of scientific practices [...] aims to avoid unwarranted philosophical impositions upon science, by attending more closely to what scientists say and do" (emphasis added). Consequently, philosophical views of scientific progress can (and perhaps should) be held accountable to what practicing scientists say and do in their research articles. The aim of this study has been to shed light on what practicing scientists say and do in their research articles as far as scientific progress is concerned.

\section{Conclusion}

The aim of this paper has been to contribute to the debate over the nature of scientific progress in philosophy of science by taking an empirical approach. By employing the methods of data science and corpus linguistics, the following philosophical accounts of scientific progress were tested against scientific practice: the semantic account of scientific progress (i.e., scientific progress in terms of truth), the epistemic account of scientific progress (i.e., scientific progress in terms of knowledge), and the noetic account of scientific progress (i.e., scientific progress in terms of understanding). Overall, the results of this quantitative, corpus-based study lend some empirical support to the epistemic and the noetic accounts over the semantic account of scientific progress, for they suggest that scientists use the progress terms 'knowledge' and 'understanding' significantly more often than the progress term 'truth' when they talk about the aims or goals of scientific research in their published works. But the results of this study do not favor the epistemic account over the noetic account, or vice versa, for they reveal no significant differences between the frequency with which practicing scientists use the terms 'knowledge' and 'understanding' when they talk about the aims or goals of scientific research in their published works. The philosophical significance of these findings consists in providing empirical evidence against which to test one's philosophical accounts of scientific progress, if one is so inclined. For, as Machery (2016, p. 480) puts it, "if we can show experimentally that a candidate rational reconstruction [or philosophical account] of a given concept $x$ has nothing or little to do with scientists' unreconstructed use of $x$, then this gives us a strong reason to assume that the reconstruction is erroneous."

\section{Acknowledgments}

I am very grateful to two anonymous reviewers of Synthese for their invaluable comments on earlier drafts of this paper.

\footnotetext{
${ }^{10}$ Although, according to Lakatos (1971, p. 91), "any rational reconstruction of history needs to be supplemented by an empirical (socio-psychological) 'external history'.”
} 


\section{References}

Albert, C. H., Yoccoz, N. G., Edwards Jr., T. C., Graham, C. H., Zimmermann, N. E., and Thuiller, W. (2010). Sampling in Ecology and Evolution—Bridging the Gap between Theory and Practice. Ecography 33 (6): 1028-1037.

Beebe, J. R. and Dellsén, F. (2020). Scientific Realism in the Wild: An Empirical Study of Seven Sciences and History and Philosophy of Science. Philosophy of Science 87 (2): 336-364.

Beifiori, A. (2011). Dynamics Induced by the Central Supermassive Black Holes in Galaxies. Publications of the Astronomical Society of the Pacific 123 (902): 514-515.

Bird, A. (2007). What is Scientific Progress? Noûs 41 (1): 64-89.

Bird, A. (2008). Scientific Progress as Accumulation of Knowledge: A Reply to Rowbottom. Studies in History and Philosophy of Science Part A 39 (2): 279-281.

Bogdan, M., van den Berg, E., Sabatti, C., Su, W., and Candès, E. J. (2015). Slope-Adaptive Variable Selection via Convex Optimization. The Annals of Applied Statistics 9 (3): 1103-1140.

Bolinska, A. and Martin, J. D. (2020). Negotiating History: Contingency, Canonicity, and Case Studies. Studies in History and Philosophy of Science Part A 80: 37-46.

Cevolani, G., and Tambolo, L. (2013). Progress as Approximation to the Truth: A Defence of the Verisimilitudinarian Approach. Erkenntnis 78 (4): 921-935.

Chang, H. (2007). Scientific Progress: Beyond Foundationalism and Coherentism. Royal Institute of Philosophy Supplements 61: 1-20.

Curto, V. E. and Fryer Jr., R. G. (2014). The Potential of Urban Boarding Schools for the Poor: Evidence from SEED. Journal of Labor Economics 32 (1): 65-93.

Dhanjal-Adams, K. L., Fuller, R. A., Murray, N. J., Studds, C. E., Wilson, H. B., Milton, D. A., and Kendall, B. E. (2019). Distinguishing Local and Global Correlates of Population Change in Migratory Species. Diversity and Distributions 25 (5): 797-808.

Dellsén, F. (2016). Scientific Progress: Knowledge versus Understanding. Studies in History and Philosophy of Science 56: 72-83.

Dellsén, F. (2018a). Scientific Progress, Understanding, and Knowledge: Reply to Park. Journal for General Philosophy of Science 49 (3): 451-459.

Dellsén, F. (2018b). Scientific Progress: Four Accounts. Philosophy Compass 13 (11): e12525. 
Douglas, H. (2014). Pure Science and the Problem of Progress. Studies in History and Philosophy of Science Part A 46: 55-63.

Hall. R. D. (2006). Plant Metabolomics: From Holistic Hope, to Hype, to Hot Topic. The New Phytologist 169 (3): 453-468.

Heng, B. C. and Cao, T. (2006). Milieu-Based versus Gene-Modulatory Strategies for Directing Stem Cell Differentiation: A Major Issue of Contention in Transplantation Medicine. In Vitro Cellular \& Developmental Biology - Animal 42 (3-4): 51-53.

Janack, M. (2002). Dilemmas of Objectivity. Social Epistemology 16 (3): 267-281.

Lakatos, I. (1971). History of Science and Its Rational Reconstructions. In R. C. Buck and R. S. Cohen (eds.), PSA 1970. Boston Studies in the Philosophy of Science, Vol. 8 (pp. 91-136). Dordrecht: Springer.

Laudan, L. (1977). Progress and Its Problems: Towards a Theory of Scientific Growth. Berkeley: University of California Press.

Lichtman, A. I. (1981). The Zero Divisor Problem for a Class of Torsion-Free Groups. Proceedings of the American Mathematical Society 82 (2): 188-190.

Machery, E. (2016). Experimental philosophy of science. In J. Sytsma and W. Buckwalter (eds.), A Companion to Experimental Philosophy (pp. 475-490). New York: Wiley Blackwell.

Mizrahi, M. (2013a). What is Scientific Progress? Lessons from Scientific Practice. Journal for General Philosophy of Science 44 (2): 375-390.

Mizrahi, M. (2013b). The Pessimistic Induction: A Bad Argument Gone Too Far. Synthese 190 (15): 3209-3226.

Mizrahi, M. (2016). The History of Science as a Graveyard of Theories: A Philosophers' Myth? International Studies in the Philosophy of Science 30 (3): 263-278.

Mizrahi, M. (2017). Scientific Progress: Why Getting Closer to Truth is not Enough. International Studies in the Philosophy of Science 31 (4): 415-419.

Mizrahi, M. (2020). The Case Study Method in Philosophy of Science: An Empirical Study. Perspectives on Science 28 (1): 63-88.

Mizrahi, M., and Buckwalter, W. (2014). The Role of Justification in the Ordinary Concept of Scientific Progress. Journal for General Philosophy of Science 45 (1): 151-166.

Niiniluoto, I. (2014). Scientific Progress as Increasing Verisimilitude. Studies in History and Philosophy of Science Part A 46: 73-77. 
Niiniluoto, I. (2019). Scientific Progress. In Edward N. Zalta (ed.), Stanford Encyclopedia of Philosophy (Winter 2019 Edition). https://plato.stanford.edu/archives/win2019/entries/scientificprogress/.

Park, S. (2017). Does Scientific Progress Consist in Increasing Knowledge or Understanding? Journal for General Philosophy of Science 48 (4): 569-579.

Park, S. (2019). Scientific Understanding, Fictional Understanding, and Scientific Progress. Journal for General Philosophy of Science 51 (1): 173-184.

Pitt, J. C. (2001). The Dilemma of Case Studies: Toward a Heraclitian Philosophy of Science. Perspectives on Science 9 (4): 373-382.

Rouse, J. (2007). Naturalism and Scientific Practices: A Concluding Scientific Postscript. In C. M. Mi and R. L. Chen (eds.), Naturalized Epistemology and Philosophy of Science (pp. 61-86). Amsterdam: Rodopi.

Rowbottom, P. D. (2008). N-rays and the Semantic View of Scientific Progress. Studies in History and Philosophy of Science Part A 39 (2): 277-278.

Rowbottom, P. D. (2010). What Scientific Progress is Not: Against Bird's Epistemic View. International Studies in the Philosophy of Science 24 (3): 241-255.

Rowbottom, P. D. (2015). Scientific Progress without Increasing Verisimilitude: In Response to Niiniluoto. Studies in History and Philosophy of Science Part A 51: 100-104.

Rowbottom, P. D. (2019). The Instrument of Science: Scientific Anti-Realism Revitalised. New York: Routledge.

Sauer, T. and Scholl, R. (2016). Introduction. In T. Sauer and R. Scholl (eds.), The Philosophy of Historical Case Studies (pp. 1-10). Basel: Springer.

Shan, Y. (2019). A New Functional Approach to Scientific Progress. Philosophy of Science 86 (4): 739-758.

Society for Philosophy of Science in Practice. (2006-2019). Mission Statement. Society for Philosophy of Science in Practice. Accessed November 1, 2019. https://philosophy-sciencepractice.org/about/mission-statement.

Soler, L., Zwart, S., Lynch, M., and Israel-Jost, V. (Eds.). (2014). Science after the Practice Turn in the Philosophy, History, and Social Studies of Science. London: Routledge.

Sutherland, R. (2017). Subduction Initiation and Palaeogene Climate (SIPC) in the Tasman Frontier, southwest Pacific: Forthcoming IODP Expedition 371. In Neville Exon (ed.), Exploring the Earth under the Sea: Australian and New Zealand Achievements in the First Phase of IODP Scientific Ocean Drilling (pp. 165-168). ANU Press. 
Tambolo, L. (2014). Pliability and Resistance: Feyerabendian Insights into Sophisticated Realism. European Journal for Philosophy of Science 4 (2): 197-213.

Van Fraassen, B. C. (1994). Gideon Rosen on Constructive Empiricism. Philosophical Studies 74 (2): 179-192.

Vink, C. J., Paquin, P., and Cruickshank, R. H. (2012). Taxonomy and Irreproducible Biological Science. BioScience 62 (5): 451-452.

Wiegleb, G. (1989). Explanation and Prediction in Vegetation Science. Vegetatio 83 (1-2): 1734.

Williamson, T. (2000). Knowledge and Its Limits. Oxford: Oxford University Press. 